\title{
Virtual Reality Technology Used in Civil Engineering Education
}

\author{
A.Z. Sampaio*, P.G. Henriques and O.P. Martins \\ Department of Civil Engineering and Architecture, Technical University of Lisbon, Lisbon, Portugal
}

\begin{abstract}
Where educational validity is concerned, a school of engineering can reasonably be expected to constantly update computational resources in frequent use in the professions. Virtual Reality (VR) technology could be applied as a complement to three-dimensional (3D) modelling, leading to better communication whether in vocational training, in education or in professional practice. Techniques of 3D modelling and VR were applied to the development of models related to the construction process. The 3D models created to support rehabilitation design emerge as an important tool for the monitoring of anomalies in structures and to assist decisions based on the visual analyses of alternative solutions. The VR model created to help the management of lighting systems in buildings allows the visual and interactive transmission of information related to the physical behaviour of the elements, defined as a function of the time variable. Didactic interactive models showing construction works were also developed. These applications allow the visual simulation of the physical progression of each type of work and also assist in the study of the necessary equipment needed and how it functions on site. The introduction of CAD and VR techniques in school is helpful to students in order to prepare them to consider these technologies as important supports, later in their professional practice.
\end{abstract}

Keywords: Engineering Education, Didactic Models, 3D models, Virtual Reality.

\section{INTRODUCTION}

Concerning educational tasks, the interaction allowed by three-dimensional (3D) geometric models could bring an end to passive learner attitudes which are often found in traditional academic teaching situations. In addition, virtual reality technology (VR) could be applied as a complement to 3D modelling, leading to better communication between the various stakeholders in the process, whether in training, in education or in professional practice. This role is particularly relevant to the presentation of processes which are defined through sequential stages as generally is the case in the learning of new curricular subjects. Besides this constant updating of training in the new graphic resources available to and in widespread and frequent use in professions in the fields of engineering or architecture, the school should also adapt its teaching activities to the new tools of visual communication. In fact, today, in practical subjects a variety of engineering software is used, but this requires skills and knowledge to develop economical and feasible solutions.

Educational institutions can use communication technology to access information, as a form of collaboration and communication with teachers, or as a tool for conveying educational contents, as well as a means of online teaching. A communication platform allows participants to exchange information about specific domains and interact and learn

\footnotetext{
*Address correspondence to this author at the Department of Civil Engineering and Architecture, Technical University of Lisbon, Av. Rovisco Pais, Lisbon, Portugal; Tel: +351218418328; E-mail: zita@civil.ist.utl.pt
}

cooperatively, therefore, an aspect that must be improved is the preparation of didactic materials to support teaching [1].

Today, 3D models and VR technology are used in engineering schools to aid both the lecturers and students. They offer students the opportunity to visualize the engineering concepts they learn in the classroom. Gibbon, in Electrical Engineering, uses laboratories containing operational amplifiers and a resonant circuit, based in 3D modelling tools in order to achieve a better understanding of circuit issues presented in formal lectures [2]. Other examples of computer simulation and VR projects supporting the teaching of engineering students are remote physics experiments [3], simulation control testing [4] and virtual laboratories [5].

\section{D AND VR MODELS IN AEC}

The use of CAD and VR systems is helpful in areas such as Architecture, Engineering and Construction (AEC). However, the introduction of these new technologies into designers' actual practice has been anything but smooth [6].

At present, when carrying out a project, the use of graphic systems and, in particular, those relating to 3D modelling, makes a very positive contribution towards improving the transmission of rigorously correct technical information and, in general, to the understanding of spatial configurations in their environment. This means of expression surpasses a drawing, a picture or a diagram [7].

\section{Architecture}

The results of the architectural design of a building are usually several drawings, which, lately, are often complemented by 3D models. Architects create 3D models of 
houses so that their clients can more clearly understand what the house will look like when built.

The development of Computer Aided Design (CAD) programs has been changing design methodology, at least in part. In general, designers approve of the use of CAD since because it improves designing, but mostly CAD is still used only as drawing aid. However, the process involved in design projects could easily derive clear benefits from the use of CAD because it can make drafting and the creation of alternatives quicker and more effective throughout several stages of designing, including the conception phase. For that, however, it is not enough for designers to learn to use CAD properly, they also have to learn how to create and to support their activity with it, which requires, also, a new way of thinking and reacting to CAD [8].

\section{Construction}

Models concerning construction need to be able to generate changes in the project geometry. The integration of geometric representations of a building together with scheduling data related to construction planning information is the basis of 4D (3D + time) models. Thus, in this field, 4D models combine 3D models with the project timeline, and VR technology has been used to render $4 \mathrm{D}$ models more realistic allowing interaction with the environment representing the construction site. 4D models are being used to improve the production, analysis, design management and construction information in many phases and areas of construction projects [9]. VTT Building Technology has been developing and implementing applications based on this technique providing better communication between the partners in a construction project [10]. Note the contribution of VR to support conception design [11], to introduce the plan [12] and to follow the progress of constructions [13].

The didactic VR models presented in the text shows the sequence of construction processes allowing step-by-step visualization. The models concern a wall, as a significant component of a building and two methods of bridge construction, each with different degrees of detail and technical information. The target users of these models are Civil Engineering students. Here, the VR technology was applied for educational purposes.

\section{Rehabilitation}

Rehabilitation is a type of construction work where the final result is of utmost importance and which must be evaluated at a very early stage, before any decision or construction work becomes definitive. Two recent pieces of work related to Bologna master's theses were developed based on this technology. The students J. Neves and B. Martins had to learn 3D advanced modelling. In both cases, 3D models appear as an important tool for anomaly surveillance in the structures and for supporting decisions based on the visual analyses of alternative rehabilitation solutions [14]:

- Neves studied an historic building that was submitted to a rehabilitation process that includes the detection of structural anomalies, the replacement of damaged resistant elements and the adaptation of the building to new uses (Fig. 1). This application clearly demonstrated that the
3D geometric model allowed a quicker understanding of the structural organisation of the building and a useful tool for the surveying and mapping of its damages.

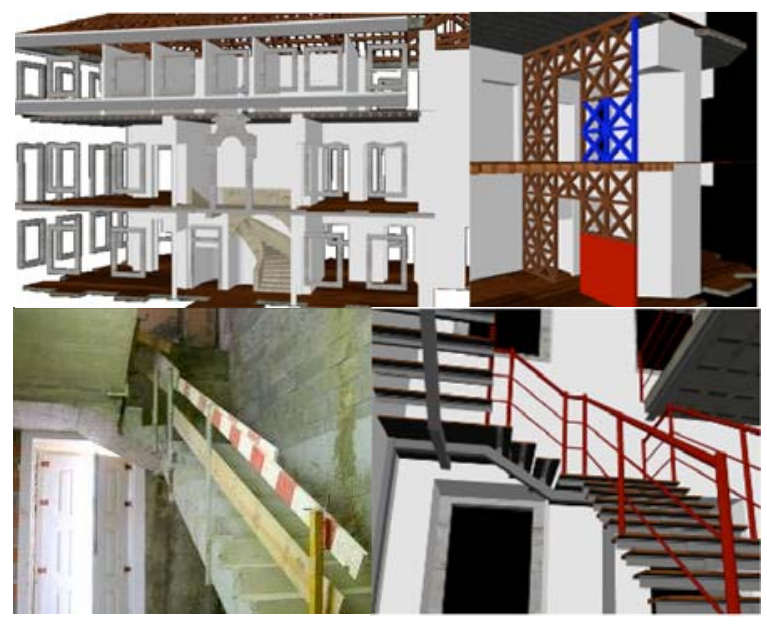

Fig. (1). Perspectives of the historic building 3D model and alternative solutions for the stairs.

- Martins considered the installation of new sanitary equipment in an old building, which presents a significant degree of dilapidation. In this case, two alterative solutions were worked out and modelled (Fig. 2). By manipulating the models, the understanding of the organization of the interior space is quite clear, better then that gained by just analyzing plan drawings. In both solutions the data for the sanitation system specifications, the quantity of pipe elements for hot and cold water supplies, the quantity and types of material applied to the interior surface of walls and on the floor were worked out. The 3D models helped work out this kind of data and also to identify incompatibilities in the introduction of new elements within old structures.

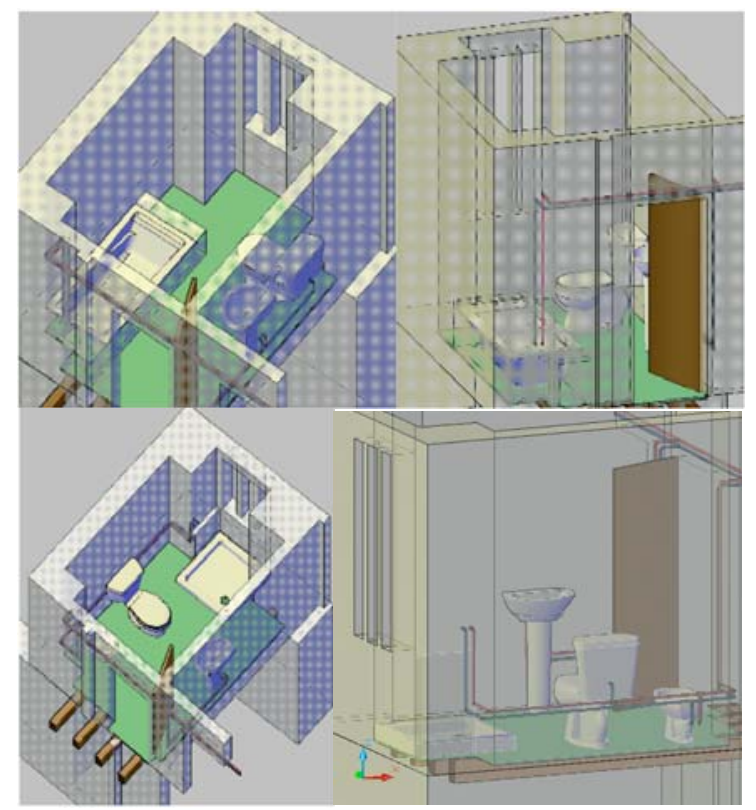

Fig. (2). 3D models of two alterative solutions. 
These situations contribute to the acceptance of the use of CAD, not only as a good "drawer", but also as a useful tool in the analyses of rehabilitation work. Thus, teaching CAD in school induces students into considering this technology as an important support for their later professional practice, and also enables the link between CAD systems and engineering theory.

\section{VR Interactive Models}

Virtual reality is a technology that allows users to explore and manipulate $3 \mathrm{D}$ interactive environments in real time. VR is seen today as an integrating technology, with great potential for communication between project participants, and most recently, as a tool for the support of decision-making.

The main aim of a research project, which is now in progress at the Department of Civil Engineering of the Technical University of Lisbon, is to develop virtual models as tools to support decision-making in the planning of construction management and maintenance.

A first prototype concerning the lighting system was developed [15]. It integrates VR system and a computer application implemented in Visual Basic (VB) language. The model allows the examination of the physical model, visualizing, for each element modelled in 3D and linked to a database, the corresponding technical information concerned with the wear and tear aspects of the material, defined for that period of time (Fig. 3). In addition, the analysis of solutions for maintenance work or substitution and inherent cost are predicted, the results being obtained interactively and visibly in the virtual environment itself.

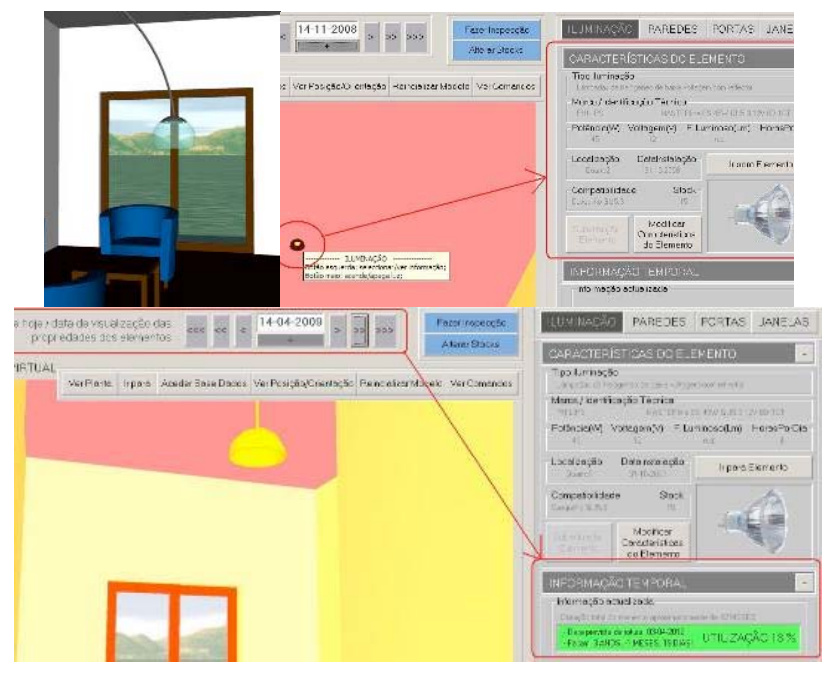

Fig. (3). VR model and updated information concerning lighting elements.

The model is easy to use and does not require sophisticated computer skills an advantage as many users may not be information technology experts. So, the prototype can be manipulated by partners interested in creating, transforming and analyzing data in order to obtain results and to make decisions. The aim is that the virtual model should be able to be applied directly over the 3D models of new constructions.

\section{Learning CAD and VR in School}

An architecture and engineering school can be expected to constantly update computational resources which are in frequent use in the professions. Actually a set of curricular tools was devised to accomplish this goal with the updated undergraduate program. As a result, some schools introduced CAD courses into the first years of their programs. Frequently, the computer is still used as a drafting tool, but the actual goal is to give students the opportunity to use the 3D models as a conceptual tool, as a preferential means of communication and as a support to elaborate alternatives in building design easily.

At the Technical University of Lisbon, in Computer Assisted Drawing $\left(1^{\text {st }}\right.$ year $)$, included in the Integrated Masters syllabus in Civil Engineering, the adaptation has been gradual, accompanying the development of new graphics systems/products supporting plan drawing and modelling [16].

The cases referred to above, concerning 3D rehabilitation models and the interactive VR prototype supporting decision-making in maintenance, are examples allowed at school both for learning and for training students in using these new graphical products.

\section{DIDACTIC VR MODELS}

The aim of the practical application of the developed didactic virtual models is to provide support in Civil Engineering education namely in those disciplines related to bridges and construction process, both in classroom-based education and e-learning technology. The virtual model can be interactively manipulated allowing the teacher or student to monitor the physical evolution of the work and the construction activities inherent in its progress.

Specialists in construction processes and bridge design were consulted and involved in the development of the educational models in order to obtain efficient and accurate didactic applications. The selected examples are three elementary work situations:

The first concerns the building of an external wall, a basic component of a building [17]; the second presents the cantilever method of bridge deck construction, a frequent construction technique [18]; and the last concerns the incremental launching method of bridge deck construction [19].

The applications developed make it possible to show the physical evolution of the tasks, to monitor the planned construction sequence, and to see the details of shape of every construction component. They also assist the study of the necessary type of type of equipment type and operational method for the construction methodologies.

A major consideration when modelling 3D environments is what exactly to show: the objects to be displayed and the details of each of these must be coherent with the aim of the teacher or designer. Developing didactic models for students means creating technical tasks, at a level that could be understood by undergraduate students. In addition, the use of VR techniques in the development of these didactic applications is helpful to education, since it improves the efficiency of the models in order to allow the interactivity with each simu- 
lated task. Therefore, this new concept of VR technology applied to didactic models brings new perspectives to Civil Engineering education.

\section{VR Model of the Wall}

The model of a masonry cavity wall corresponds to one of the basic components of a standard construction. To enable the visual simulation of the wall construction, the geometric model generated is composed of a set of elements, each representing one component of the construction. The definition of the 3D model of an exterior wall of a conventional building comprises (Fig. 4): the structural elements (foundations, columns and beams), the vertical filler panels (with the thermal isolation plate placed between the brick panels and the stone slabs placed on the exterior surface) and two cavity elements (door and window).

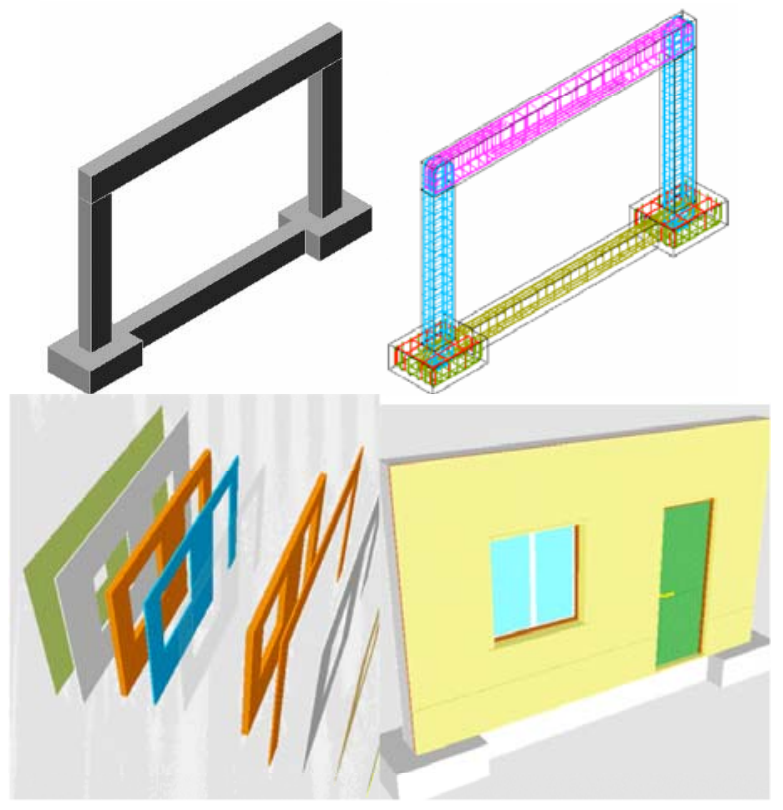

Fig. (4). Steel reinforcements 3D models of the structural elements, the vertical filler panels and the door and window openings.

The complete geometric model was transferred to the VR system EON [20]. In this system, the visual simulation of the wall building process was programmed, following a realistic plan of the construction progress. The order in which components are consecutively exhibited and incorporated into the virtual model, properly represent the real evolution of the wall under construction:

- During the animation, the student can control the length of time that any phase is exhibited and observe the model using the most suitable camera and zoom positions for a correct perception of the details of construction elements (Fig. 5);

- It is possible to highlight the incorporated component at each new phase and to examine it in detail (Fig. 6);

- Included, under the window in which the virtual scene is exhibited, is a bar, which shows the progress of the construction. Throughout the animation, the bar is progressively filled, with small rectangles symbolizing the per- centage of each phase, in relation to the completed wall construction. Through symbols it represents the diagrams normally used on construction plans (Fig. 6);

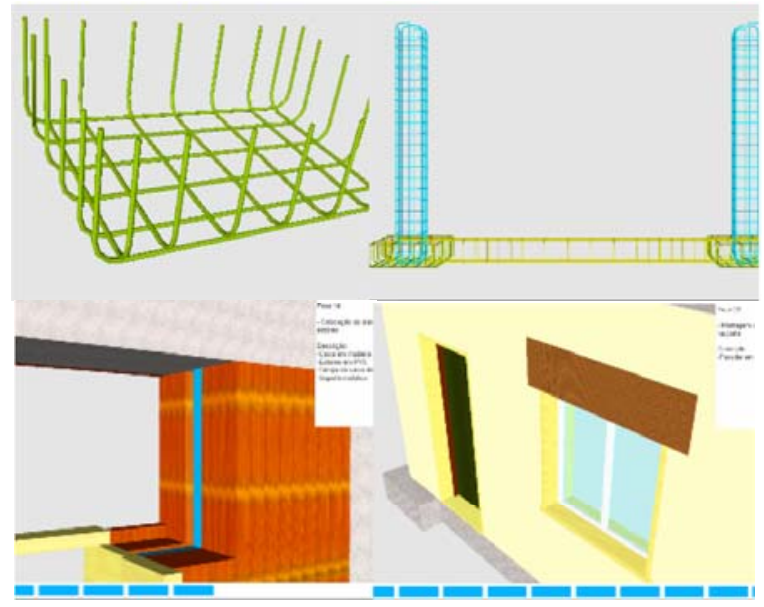

Fig. (5). Time length control and zoom positions.

- Simultaneously, with the visualization of each phase, a text is shown (in the upper right corner of the window, Fig. 6), giving data related to the shown stage, namely, its position within the construction sequence, the description of the activity and the material characteristics of the element incorporated.

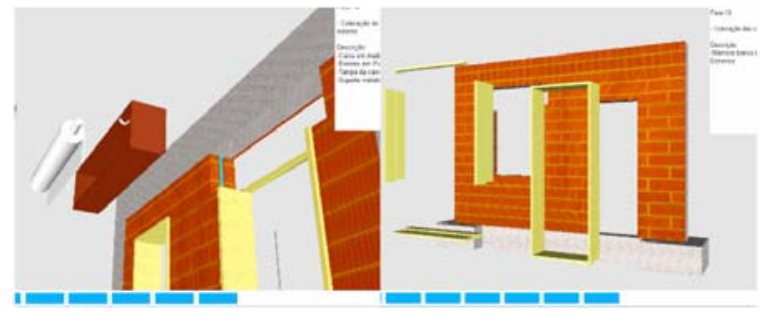

Fig. (6). Elements from the global model of the wall.

The development of the model was supported by a specialised engineer working in construction which guarantees that the model shows a valid construction sequence and that the configuration of each component was defined accurately. The models support CAD and Construction subjects.

\section{VR Model of the Cantilever Method of Bridge Construc- tion}

The second model created allows the visual simulation of the construction of a bridge using the cantilever method. Students are able to interact with the model dictating the rhythm of the process, which allows them to observe details of the advanced equipment and of the elements of the bridge (pillars, deck and abutments). The sequence is defined according to the norms of planning in this type of work.

The North Viaduct of the Bridge Farm, in Madeira, Portugal, was the case selected for representation in the virtual environment. In cross-section, the deck of the viaduct shows a box girder solution, its height varying in a parabolic way along its three spans. The most common construction tech- 
nique for this typology is the cantilever method. A computer graphic system which enables the geometric modelling of a bridge deck of box girder typology was used to generate, 3D models of deck segments necessary for the visual simulation of the construction of the bridge (Fig. 7).

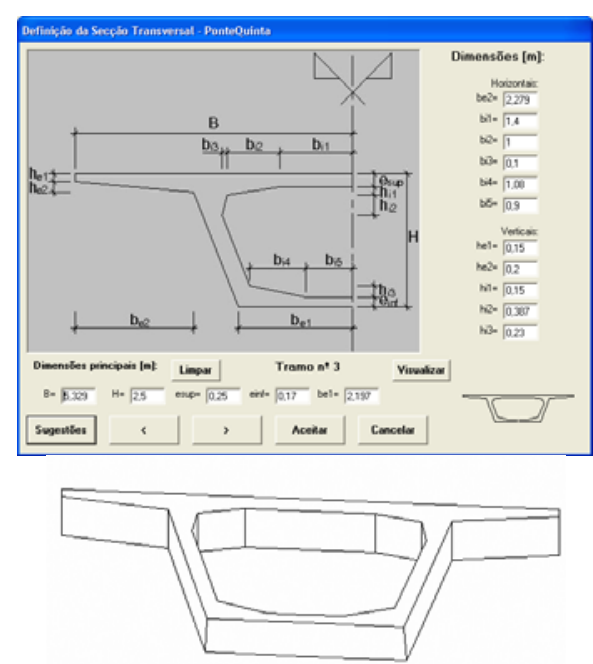

Fig. (7). Interface to describe cross-sections and the 3D model of a deck segment.

To complete the model of the bridge, the pillars and abutments were modelled. Then followed the modelling of the advanced equipment, which is composed not only of the form traveller, but also the formwork adaptable to the size of each segment, the work platforms for each formwork and the rails along which the carriages run (Fig. 8). As, along with the abutments, the deck is concreted with the false work on the ground, the scaffolding for placement at each end of the deck was also modelled (Fig. 8).

The 3D model of the construction environment was then transposed to the virtual reality EON system.
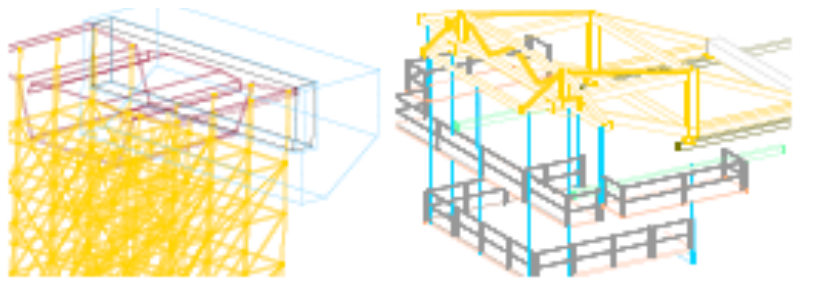

Fig. (8). 3D models of the scaffolding and the advanced equipment.

The support of a bridge design specialist was essential in obtaining an accurate model, not only of the geometry definition of components of the bridge and devices, but also of the establishment of the progression sequence and of the way the equipment operates (Fig. 9):

- This method starts by applying concrete to a first segment on each pillar, the segment being long enough to install the work equipment on it;

- The construction of the deck proceeds with the symmetrical execution of the segments starting from each pillar, using the advanced equipment;
- The continuation of the deck, joining the cantilever spans, is completed with the positioning of the closing segment;

- Finally, the zone of the deck near the supports is constructed, using a false work resting on the ground.

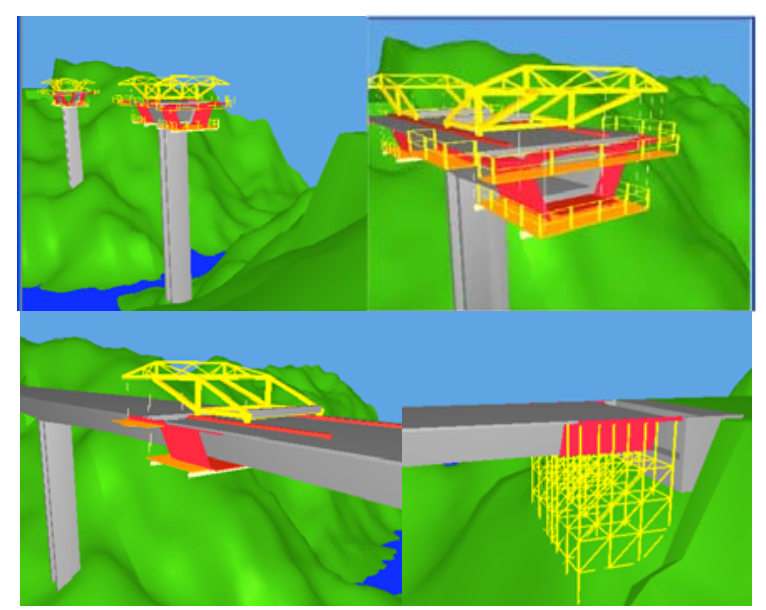

Fig. (9). Construction sequence.

Moving the camera closer to the bridge model and applying to it routes around the zone of interest, the student, interacting with the virtual model, can follow the sequence specifications and observe the details of the configurations of the elements involved.

\section{VR Model of the Incremental Launching Method of Bridge Construction}

Another interactive model concerning construction of deck bridges to support Civil Engineering education was created. The construction of bridge decks using the method on incremental launching has existed since the 60s. The incremental launching method consists of casting $15 \mathrm{~m}$ to $30 \mathrm{~m}$ long segments of the bridge deck in a stationary formwork which push a completed segment forward with hydraulic jacks along the bridge axis.

Every element needed in the virtual scenario was modelled and then the interaction was programmed using the some software based on the VR technology, the EON Studio. The 3D model of all elements was generated using AutoCAD:

- The metal elements supporting the form and the formwork itself composed by beams and panels, made of wood, were created;

- To represent the reinforcements a steel mesh was designed;

- With the objective of allowing some immersive capacity to the model, the river was represented by a surface with mixed colours and the selected panorama simulated a typical environment of river banks.

During the animation, the position of the camera and its movement are synchronized to show the details of the elements or the assembly type and also an overview of the working place. In order to report an overview of the con- 
struction site the camera points initially to the casting yard. At this stage just the abutments, piers and beams of the foundation of the yard are visible (Fig. 10).

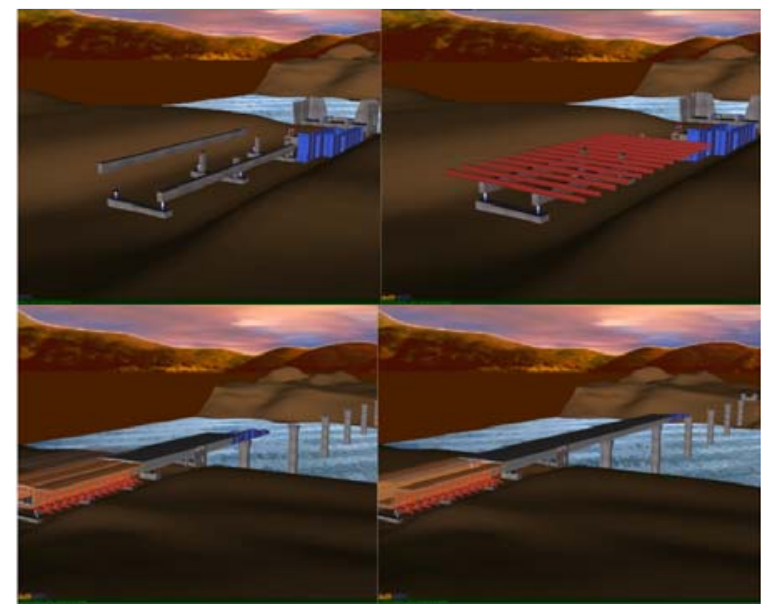

Fig. (10). The casting yard and a sequence of the incremental launches of the deck.

The elements that make up the interior false work are placed incrementally, starting with the metallic support, followed by the longitudinal beams and finishing with the implementation of shuttering panels. Next, the assembly of the launching nose is installed. After casting the first segment the displacement of this element takes place (Fig. 11).

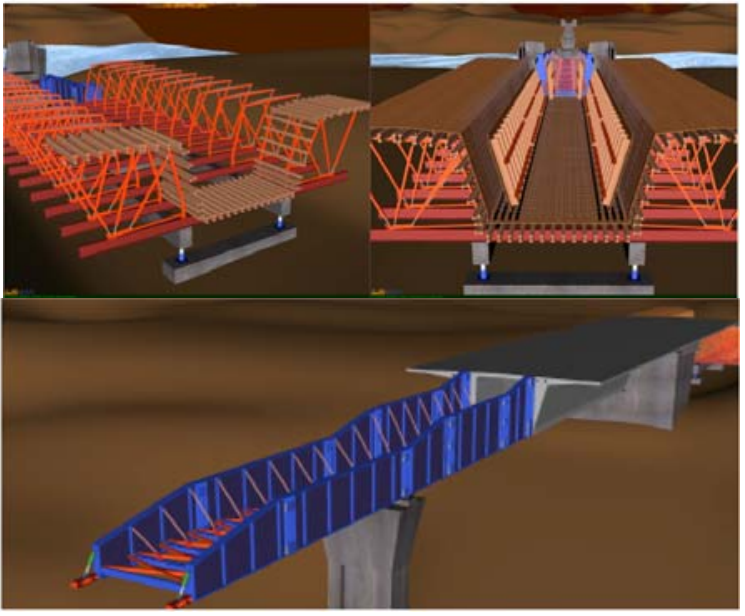

Fig. (11). Visualization of the formwork structure and the metallic launching nose.

Already in the final phase of construction the casting equipment is removed and the area is covered with soil. Finally the guards along with other finishing elements are positioned (Fig. 12).

The model was them made accessible to students and teachers of other institutions related to Civil Engineering using the platform developed by the Lisbon Technical University as part of their e-school activities. This model presents a great complexity of geometry and material concerning the different elements used in a real work process. It pro- vides an immersive capacity inherent in the virtual world and it has a menu of events which allows the students and teachers to select a specific part (Fig. 13).

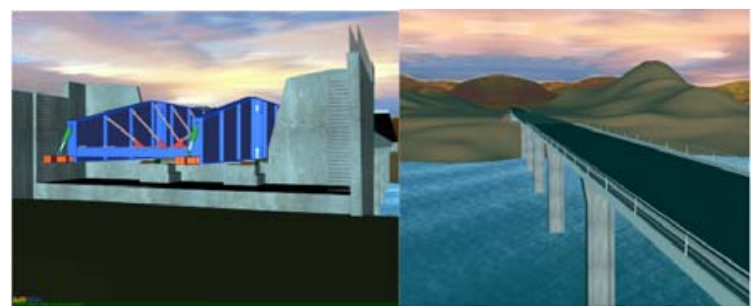

Fig. (12). The guards and also other finishing elements are positioned.

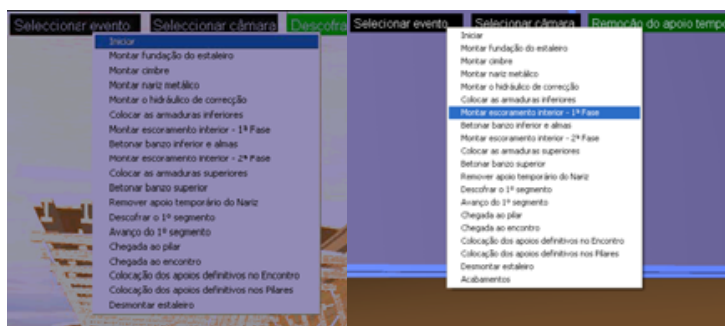

Fig. (13). Menus of events.

The user is able to grasp the most important details of the construction method because of the camera movement which consistently shows the model throughout all the sequences of events http://www.octaviomartins.com/lancamentoIncremental

\section{Learning Aspects}

At present, didactic models are used in face-to-face classes of subjects of Civil Engineering curricula: Computer Aided Drawing ( $1^{\text {st }}$ year) Construction Process ( $4^{\text {th }}$ year) and Bridges $\left(5^{\text {th }}\right.$ year). They are placed on the webpage for each subject thus being available for students to manipulate. The student should download the EON Viewer application available at, http://www.eonreality.com/

The traditional way to present the curricular subjects involved in those virtual models are 2D layouts or pictures. Now, the teacher interacts with the 3D models showing the construction sequence and the constitution of the modelled type of work. Essentially, the models are used to introduce new subjects:

- As in Computer Aided Drawing, students have to define and draw structural plants over the architectural layouts, the virtual model of the wall helps to explain the connection between the architectural drawings and the structural solutions needed to support the building configuration (Fig. 14).

- In the discipline of Construction Process, in order to prepare students to visit real work sites, the teacher shows the construction animation and explains some items of the construction process of the wall, in particular, the way the iron grid work defined inside a beam or a column and specially the complexity of the relationship be- 
tween the distinct types of ironwork near the zone where the structural elements connect to each other (Fig. 15). In order to explain this issue related to the structural elements, the iron networks were created as 3D models with distinct colours. They appear on the virtual scenario following a specific planned schedule;

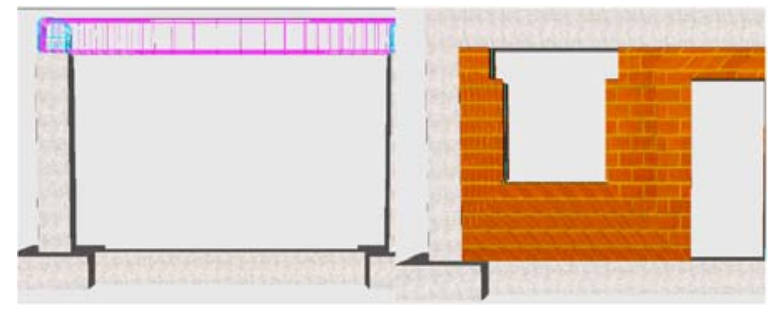

Fig. (14). The relationships between the architectural and the structural elements in a wall.
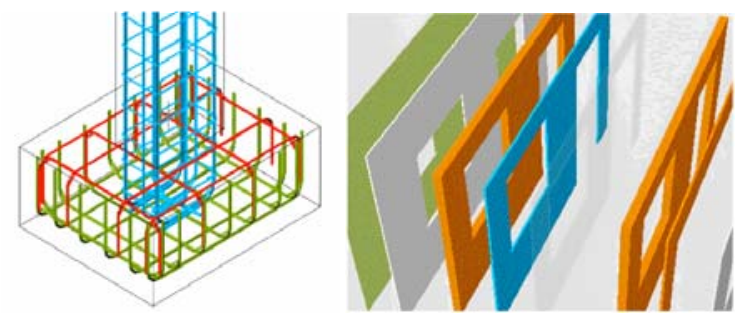

Fig. (15). Complex relationship between reinforcements and the sequence of the vertical panels.

- In addition, the type, sequence and thickness of each vertical panel that composes a cavity wall are well presented in the virtual model showing, step by step, the relationship between each other (Fig. 15);

- The deck bridge models, in particular, show the complexity associated to the construction work of the deck and illustrate in detail the movement of the equipment. In class, the teacher must explain why the process must follow both sequence of steps and the way the equipment operates. When the student, of the $5^{\text {th }}$ year, goes to a real work site he can observe the complexity of the work and better understand the progression of construction previously explained.

\section{CONCLUSIONS}

This paper has focussed on the importance of teaching CAD systems at school, not only as a good instrument for "drawings" but mostly as a helpful tool to be used to develop research work and, as a professional support in their activity as engineers.

Regarding Bologna, these two recent examples of 3D modelling were created to support rehabilitation design. The models were useful to the outcome of building anomaly surveillance and to workout alternative solutions. The VR model created to help the management of lighting systems in buildings was developed within a research project in school. It enables the visual and interactive transmission of information related to the physical behaviour of the elements, defined as a function of the time variable. Thus, teaching CAD and VR technologies in school may well induce students to consider this knowledge as elementals in their future professional activity, while to establishing the link between CAD systems and engineering theory.

It has also been demonstrated, through the examples presented here, how the technology of VR can be used in the elaboration of teaching material of educational interest in the area of construction processes. The advantage of introducing new technologies into the creation of didactic material suitable for university students and technical instruction should be made known and applied. The didactic applications support the explanation of topics related to construction work. These models are used in disciplines involving construction and bridges in courses in Civil Engineering and Architecture. The main objective of the practical application of the didactic model is to support class-based learning. In addition, it can be used in distance training based on e-learning platform technology.

There are many other possibilities for the creation of computational models mainly where the subject matter is suitable for description along its sequential stages of development. The applications with these characteristics make the advantage of using techniques of VR more self-evident, especially when compared to the simple manipulation of complete models which cannot be broken down. The pedagogical aspects and technical concepts must be integral elements in the design and creation of these models.

\section{REFERENCES}

[1] C. Gomes and H. Caldeira, "Virtual learning communities in teacher training", In International Conference on Education, Innovation, Technology and Research in Education, IADAT, International Association for the Development of Advances in Technology, Bilbao: Spain, 2004, pp. 82-85.

[2] G.J. Gibbon, "Combining theory and experimentation to develop inductive learning skills in an electric circuits course", In ICEE 2008 Conference, Pécs and Budapest: Hungary, 2008, CD Rom 5pgs.

[3] M. Ozvoldova, P. Cernansky, F. Schuer, and F. Lustig, "Internet remote physics experiments in a student laboratory", in Innovations 2006, Vol. 25, W. Aung, et al. Ed. iNEER, Arlington, VA, pp. 297-304.

[4] J. Su, J. Hu, and Y. Ciou, "Low-cost simulated control experimentation conducted in Electrical Engineering Department of National Yulin University of Science and Technology", in Innovations 2006 , Vol 35, W. Aung, et al. Ed. iNEER, Arlington, VA, pp. 397-408.

[5] A. S. Safigianni, and S.K. Pournaras, "Virtual laboratory arrangement for measuring characteristic power system quantities", in Innovations 2008, Vol 34, W. Aung, et al. Ed. iNEER, Arlington, VA, pp. 379-391.

[6] J. Duarte, "Inserting new technologies in undergraduate architectural curricula: A case study", in eCAADe 07, 25 ${ }^{\text {th }}$ Conf. of Education and Research in Computer Aided Architectural Design in Europe, Frankfurt am Main, Germany, 2007, pp.423-430.

[7] A.Z. Sampaio, and P.G. Henriques, "Visual simulation of civil engineering activities: Didactic virtual models", in WSCG 2008, $16^{\text {th }}$ International Conference in Central Europe on Computer Graphics, Visualization and Computer Vision, Plzen, Czech Republic, 2008, pp. 143-149.

[8] H. Penttila, "The state-of-the-art of finnish building product modelling methodology", in Computer Aided Architectural Design Futures 2005 Wien, B. Martens, and A. Brown, Eds. Springer Verlag. 2005, pp. 225-239.

[9] M. Fischer, and J. Kunz, "The scope and role of information technology in construction", in CIFE Centre for Integrated Facility Engineering in Finland, technical report \#156, Stanford University, 2004. 
[10] J. Leinonen, K. Kähkönen, and A. Retik, "New construction management practice based on the virtual reality technology", in 4D CAD and Visualization in Construction: Developments and Applications, R.A. Raja, I. Flood, J. William, O'Brien, Eds. A.A. Balkema Publishers: The Netherland 2003, pp. 75-100.

[11] F. Petzold, O. Bimber, and O. Tonn, "CAVE without CAVE: onsite visualization and Design Support in and within existing building", in eCAADe 07, 25 ${ }^{\text {th }}$ Conf. of Education and Research in Computer Aided Architectural Design in Europe, Frankfurt, Germany, 2007, pp. 161-168.

[12] A. Khanzode, M. Fisher, and D. Reed, "Challenges and benefits of implementing virtual design and construction technologies for coordination of mechanical, electrical, and plumbing systems on large healthcare project", in CIB, $24^{\text {th }}$ W78 Conference, Maribor, Slovenia, 2007, pp. 205-212.

[13] M. Fischer, "4D CAD - 3D Models incorporated with time schedule", CIFE Centre for Integrated Facility Engineering in Finland, VTT-TEKES, Helsinki, Finland, 2000.

[14] A.Z. Sampaio, J.G. Neves, and B. Martins, "3D models applied in building rehabilitation", in CC2009, $11^{\text {th }}$ International Conference on Civil, Structural and Environmental Engineering Computing, Funchal, Madeira, Portugal, 2009, paper 269.

[15] A.Z. Sampaio, M. Ferreira, and D.P. Rosário, "Interactive virtual application on building maintenance: The lighting component", in
IRF2009, $3^{\text {rd }}$ International Conference on Integrity, Reliability and Failure: Challenges and opportunities, Symposium Visualization and human-Computer Interaction Porto, Portugal, 2009, pp. 221222.

[16] A.Z. Sampaio, P.G. Henriques, and C.O. Cruz, "Visual simulation of construction activity supported on VR models: e-Learning tools", in IADIS International Conference e-Society, Barcelona, Spain, 2009, pp. 284-291.

[17] A.Z. Sampaio, and P.G. Henriques, "Building activities visualized in virtual environments", in eCAADe 07, $25^{\text {th }}$ Conference of Education and Research in Computer Aided Architectural Design in Europe, Frankfurt, Germany, 2007, pp. 85-89.

[18] A.Z. Sampaio, P.G. Henriques, and P.S. Ferreira, "Virtual Reality technology applied in Civil Engineering education", in m-ICTE 2006, IV International Conference on Multimedia and ICT's in Education, Seville, Spain, 2006, pp. 1351-1355.

[19] O. Martins, and A.Z. Sampaio, "The incremental launching method for educational virtual model", in CDVE2009, $6^{\text {th }}$ International Conference on Cooperative Design, Visualization and Engineering, Luxembourg City, Luxembourg, 2009, pp. 329-332.

[20] EON, "Introduction to working in EON Studio", EON Reality, Inc. http://www.eonreality.com/ [Accessed Oct. 23, 2009].

(C) Sampaio et al.; Licensee Bentham Open.

This is an open access article licensed under the terms of the Creative Commons Attribution Non-Commercial License (http://creativecommons.org/licenses/ by-nc/3.0/) which permits unrestricted, non-commercial use, distribution and reproduction in any medium, provided the work is properly cited. 